\title{
Taiwanese Children's Attitudes about English as a Foreign Language Learning
}

\author{
Yu-Hsiu Liu ${ }^{1, *}$ \\ ${ }^{1}$ Departemnt of Foreign Languages and Literature, Huafan University, Taiwan \\ *Correspondence: Department of Foreign Languages and Literature, Huafan University No. 1,Huafan Rd., Shihding \\ Dist., New Taipei City 223, Taiwan. E-mail: nicolebeart@gmail.com
}

Received: September 11, 2016

Accepted: September 16, 2016 Online Published: September 18, 2016

doi:10.5430/wjel.v6n3p1

URL: http://dx.doi.org/10.5430/wjel.v6n3p1

\begin{abstract}
For children in Taiwan, learning English has sometimes been viewed as a burden because they are required to learn English by either parents or schools. Given that English is officially taught as a subject in elementary schools, children have to study English diligently if they aspire to achieve academic success. Recognizing the need for learning and studying English, little research, nonetheless, has investigated children's opinions regarding the learning of English language in Taiwan. To fill this gap, this study examined twenty-five Taiwanese fifth graders' attitudes about learning English at a primary school in Taipei City. Results showed that most Taiwanese children had positive attitudes about learning English. Despite the pressure of learning English, they still agreed with the government's English learning policy. Suggestions concerning Chinese and English bilingual education practiced in Taiwan are also offered to benefit teachers and educators at the primary school levels.
\end{abstract}

Keywords: English learning; bilingual education; attitudes; Taiwanese children

\section{Introduction}

Learning English has become such a worldwide trend that English is now recognized as a global language (EGL) (Crystal, 1997). The trend of learning English also impacts Taiwan greatly on its bilingual education policy. The Ministry of Education of Taiwan has made a policy that primary students, from the third up to the sixth grade, must learn English in addition to their mother tongue, Mandarin Chinese. As the policy defines, it is significant for children to learn English as early as possible and children are expected to have basic and fluent communication skills in English (The Guidelines for a 9-Year Joint Curricula Plan, 2000).

This policy indeed accommodates the need to train the next generation to be bilingual in both Chinese and English. Nevertheless, the practice of Chinese and English bilingual education has also caused some problems for schools and parents. Some schools, for instance, may have encountered difficulties in finding qualified English teachers; thus, the English teaching quality among these schools remains questionable. As for parents, since they wish their children to be competitive in learning, they continue pushing their children to learn more English. Among those problems, the fundamental one that requires more research is children's attitudes about learning English. What do children think about learning English? What causes children to like or dislike learning English? Do they agree with the government's bilingual education policy?

To answer the above questions, I designed a questionnaire to explore Taiwanese children's attitudes about learning English in educational settings. Examining children's attitudes will assist the government in making a better language policy that meets the needs of children.

\section{Literature Review}

Bilingual education, according to Lam (2001), refers to "education using both languages [learners' native language and a second or foreign language] as media of instruction and/or having bilingualism as a goal of education" (p. 95). Bilingual education has been implemented worldwide in many countries, such as Canada, Japan, Korea, Singapore, Taiwan, and the United States, because it accommodates the need for people to be proficient in more than one 
language in this global village (Diaz-Rico \& Weed, 2002). The decision of whether to practice bilingual education is actually affected by complicated factors in association with culture, economics, and politics (Diaz-Rico \& Weed, 2002).

Bilingual education programs comprise five organizational models: a) submersion, b) English as a second language, c) transitional or early-exit bilingual education (TBE), d) maintenance or developmental bilingual education (MBE), and e) immersion (Richards, Platt, J., \& Platt, H., 1998; Diaz-Rico \&Weed, 2000). In this paper, specific attention will be paid to the MBE model since its design matches the bilingual program practiced in Taiwan. The MBE model, according to Diaz-Rico and Weed (2002), is "a bilingual program that supports education and communication in the students' primary language as well as students' heritage and culture" (p.171). In other words, students do not learn a second or foreign language at the expense of their mother tongue. Rather, they are encouraged to maintain their mother tongue and culture as a potential resource for promoting second or foreign language learning (Diaz-Rico \& Weed, 2002). Examining bilingual education in the context of Taiwan, we note that Taiwan's bilingual education should be categorized as the MBE model since all third to sixth graders must study Chinese as well as English at school under the government's bilingual education policy.

The practice of bilingual education has created several problems in Taiwan. Although the government's policy aims to help children master both the Chinese and English languages, most children fail to achieve that through the bilingual education they receive. What we observe most often is that children lack the skills necessary for effective communication inside and outside the classroom (Wu, 2002), and such a phenomenon may be due to many factors, including language anxiety or language attitudes. A substantial number of studies have indicated that foreign language learning can provoke anxiety in children (Horwitz\& Cope, 1986; Aida, 1994; Hsieh, 1999; Chan \& Wu, 2000; $\mathrm{Wu}, 2001$ ). With anxiety, children tend to perform poorly in the second or foreign language (Aida, 1994; Chang, 1999). In addition to anxiety, research has shown that language attitudes and motivation (Brown, 2001; Dornyei, 2014) can determine language learning outcomes. Strong motivation and a positive attitude usually lead to a better performance (e.g., Tarhan \& Balban, 2013). Despite these findings, comparatively little research has been conducted to examine children's attitudes toward learning English in Taiwan. To bridge this gap, this study investigates how Taiwanese children perceive learning English as a foreign language (EFL) in school settings. Aside from children's attitudes, the study will investigate factors that influence their opinions of learning English.

\section{Research Question and Hypothesis}

The research question posed in this study was: "What are Taiwanese children's attitudes about learning English?" In light of previous research findings, it was hypothesized that children would have negative attitudes about learning English.

\section{Method}

\subsection{Participants}

The participants were 25 Taiwanese fifth graders in a primary school of Taipei City. The 14 male (56\%) and 11 female (44\%) participants ranged from 10 to 12 years in age. The average age of the participants was eleven. In regard to learning English, the participants studied English for at least three to seven years, with three years on average. Only one participant had traveled to an English speaking country.

\subsection{Instrument}

A self-designed questionnaire was employed to examine Taiwanese children's attitudes about learning English (see Appendix 1 for the questionnaire). To avoid misunderstandings and confusion resulting from language problems, the questionnaire was translated into the participants' mother tongue, Mandarin Chinese. The questionnaire contains sixteen questions which can be categorized into four types: checklist questions, open questions, and multiple choice and yes-or-no questions. The following table describes the themes and sub-themes inquired in the questionnaire. 
Table 1. Composition of the Questionnaire

\begin{tabular}{|c|c|c|}
\hline & Main Theme & Subtheme \\
\hline Part 1 & Background Information & None \\
\hline \multicolumn{3}{|l|}{ (5 questions) } \\
\hline \multirow{6}{*}{$\begin{array}{l}\text { Part } 2 \\
\text { (11 questions) }\end{array}$} & \multirow{6}{*}{ English Learning \&You } & Reasons to learn English (Q1) \\
\hline & & Opinions about learning English (Q2-Q3) \\
\hline & & Attitudes about learning English (Q4) \\
\hline & & Preference (Q5) \\
\hline & & Learning difficulties (Q6-Q8) \\
\hline & & Values (Q9-Q11) \\
\hline
\end{tabular}

\subsection{Data Collection and Data Analysis}

Thirty questionnaires were distributed and twenty-five were returned. The response rate was $83.3 \%$. All of the participants' responses to the questionnaire were counted, totaled, averaged in order to determine the participants' average group response.

\section{Results}

\subsection{Attitudes about Learning English}

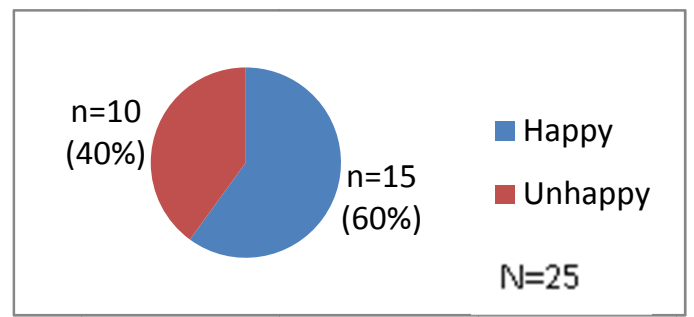

Figure 1. Attitudes about Learning English

The participants' overall attitude toward learning English was based on their responses to the fourth question on the questionnaire. As shown in Figure 1, over half of the participants reported that they were happy about learning English (60\%), while 40\% reported the opposite. Although these results may show that the participants tended to hold positive attitudes about learning English, it should be noticed that almost half of the participants displayed negative attitudes about learning English. Their negative attitudes may be accounted for by the findings below.

\subsection{Reasons for Children to Learn English}

Table 2. Reasons to Learn English

\begin{tabular}{lcc}
\hline Reasons & $\mathrm{n}$ & \multicolumn{1}{c}{$\%$} \\
\hline Pleasure & 1 & 4 \\
Requests from parents & 10 & 40 \\
School requirements & 12 & 48 \\
Friends & 2 & 8 \\
\hline Total & 25 & 100 \\
\hline
\end{tabular}

Table 2 indicates that almost half of the participants reported that they learned English for the main purpose of meeting school requirements (48\%). In addition, $40 \%$ of the participants learned English because their parents 
required them to do so. Only 4\% of the participants said they learned English for pleasure. These results show that parents and schools were two major sources contributing to children's learning of the English language.

The participants also reported several factors that may affect their motivation for learning English. The factors and their relevant findings are listed below.

a. Methods of instruction: Among the 15 participants who liked learning English, 8 indicated that English should be taught with fun $(53 \%)$.

b. Text difficulty: The participants pointed out that they would enjoy learning English if the text used is interesting and contains many pictures and topics. Texts containing complex content and difficult vocabulary usually discouraged them from learning English. For instance, among the 10 participants who disliked learning English, 8 reported that abstruse texts would demotivate them in learning English (80\%).

c. Interest in the English language: Among the 15 participants who liked learning English, 11pointed out that they liked English because of their interest in the language (73\%). One participant pointed out that learning English well would enable her to communicate with people around the world. Similarly, there were two participants sharing the same opinion, indicating that English is an international language vital to everyone.

d. Academic performance in English: Seven out of the15 subjects who liked learning English (47\%) pointed to good academic performance as a key factor that triggers them to learn and study English.

\subsection{Difficulties in Learning English}

Table 3. Difficulties in Learning English

\begin{tabular}{lcc}
\hline Difficulty & $\mathrm{n}$ & $\%$ \\
\hline Pronunciation & 4 & 16 \\
Speaking & 2 & 8 \\
Memorizing vocabulary & 5 & 20 \\
Understanding daily conversations & 8 & 32 \\
Writing in English & 6 & 24 \\
\hline Total & 25 & 100 \\
\hline
\end{tabular}

As shown in Table 3, eight participants (32\%) surveyed reported that understanding daily conversations between Americans is most difficult in learning English. Learning how to write in English was also a challenge for $24 \%$ of the participants. The participants reported having the least difficulty in speaking English (8\%).

5.4 Opinions Concerning the Government's English Learning Policy

Table 4. Opinions about the English Learning Policy

\begin{tabular}{lrc}
\hline Opinions & $\mathrm{n}$ & $\%$ \\
\hline agree & 18 & 72 \\
disagree & 7 & 28 \\
\hline Total & 25 & 100 \\
\hline
\end{tabular}

Table 4 shows that $72 \%$ of the participants agreed with the government's policy that requires all third to sixth graders to study English as a subject matter in primary schools. Despite those who disagreed with the policy, the prevailing view is that the policy reasonably reflected the trend of globalization; as a result, most participants showed positive attitudes toward the government's language policy.

\section{Discussion}

The results of the present study can be summarized by pointing out, firstly, that the participants had positive attitudes 
toward learning English and that they agreed with the government's language policy. Despite their positive attitudes, children indicated that they learned and studied English at the request of their parents and schools. Understanding conversations between Americans was for them the most difficult part of learning English.

The results did not confirm my hypothesis that Taiwanese children would have negative attitudes about learning English. Different from what I had expected, most children were positive about learning English. One possible explanation is that the participants' teachers might have come to realize the importance of teaching English with fun, thus making the participants become more interested in learning English.

It is interesting to note that the participants' positive attitudes did not necessarily lead to their enjoyment of learning English. Compared to $88 \%$ of the participants who learned English at the request of parents and schools, only one percent of the participants learned English for pleasure. This finding is not surprising because previous research has shown that when a foreign language is taught as a school subject, students tend to suffer foreign language classroom anxiety (Horwitz , Horwitz, \& Cope, 1986) in addition to general learning anxiety. That's why some participants indicated that poor academic performance in English would discourage them from learning or studying English.

With respect to learning difficulties, the participants reported having problems in understanding conversations between Americans, followed by problems in writing and memorizing vocabulary. It is rather surprising that, contrary to previous research findings (e.g., Wu, 2002), they had few problems in speaking English. This inconsistency may result from the participants' lack of experience in speaking English. Limited experience might have caused them to have comparatively little difficulty in learning speaking skills. Finally, the participants' view about the government's language policy also echoes their positive attitudes toward learning English. Globalization and the prevalence of media might have made the participants notice the need to become proficient Chinese-English bilinguals, so they supported the government's language policy.

These findings suggest that primary school teachers and educators should be aware of the social aspect of foreign language learning and teaching. Bilingual education should be practiced considering the needs of students, teachers, and schools. In addition, teachers need to create a relaxing and interactive learning environment for students if they are to help students develop interest in foreign language learning. For a better bilingual education, educators and teachers should incorporate students' culture and language into the foreign language curriculum because excluding students' culture from language teaching may actually jeopardize their cultural identities (Cazden, 1986). By teaching with and through culture, language teachers can gradually remove students' anxiety in learning a foreign language and make learning much easier and fun for their students.

\section{Conclusion}

This study was conducted to investigate Taiwanese children's attitudes about learning English. The overall results showed that, despite facing the pressure caused by parents and schools, the participants were positive about learning English and that they agreed with the government's language policy, which requires all third to sixth graders to study English as a subject matter in primary schools. A caution, however, should be made is that, due to the small number of participants in this study, the results should not be generalized to all Taiwanese children. Taiwanese children's attitudes about learning English may actually vary depending on their age, proficiency, and previous learning experience. Future research may find it useful to examine further the potential influence of parents and schools on children's attitudes about learning English.

\section{References}

Aida, Y. (1994). Examination of Horwitz, Horwitz, and Cope's construct of foreign language anxiety: The case of students of Japanese. Modern Language Journal, 78(2), 155-168. http://dx.doi.org/10.1111/j.1540-4781.1994.tb02026.x

Brown, H. D. (2001). Teaching by principles: An interactive approach to language pedagogy. New York: Addison Wesley Longman, Inc.

Cazden, C. (1986). ESL teachers as language advocates for children. In P. Rigg \& D. S. Enright (Eds.), Children and ESL: Integrating perspectives (pp.9-21). Washington, DC: Teachers of English to Speakers of Other Languages.

Chan, Y.C., \& Wu, G.C. (2000). A study of foreign language anxiety of elementary school EFL learners in Taiwan. Proceedings of the 2000 National Taipei Teachers College Educational Academic Conference, 1, 85-100. 
Chang, S.F., \& Huang, S.C. (1999). Taiwanese English learners' learning motivation and language learning strategies. Proceedings of the Sixth Conference on English teaching and learning in the Republic of China, 1, 111-128.

Crystal, D. (1997). English as a global language. New York: Cambridge University Press.

Diaz-Rico, L. T., \& Weed, K. Z. (2002). The crosscultural, language, and academic development handbook. Boston: Allyn \& Bacon.

Dornyei, Z. (2014). Motivation in second language learning. In M. Celce-Murcia, D. Briton \& M. Snow (Eds.), Teaching English as a second or foreign language ( $4^{\text {th }}$ ed., pp. 518-531). Boston: National Geographic Learning.

Horwitz, E.K., Horwitz, M.B., \& Cope, J. (1986). Foreign language classroom anxiety. Modern Language Journal, 70(2), 125-132. http://dx.doi.org/10.1111/j.1540-4781.1986.tb05256.x

Hosch, H. M. (1984). Attitudes toward bilingual education: A view from the border. El Paso, Texas: Texas Western Press.

Hsieh, C.L. (1999). The relationship between anxiety and the use of communication strategies in L2 context. Unpublished master's thesis, National Taiwan Normal University, Taipei, Taiwan.

Lam, A. (2001). Bilingualism. In R. Carter \& D. Nunan (Eds.), The Cambridge guide to teaching English to speakers of other languages. New York: Cambridge University Press. http://dx.doi.org/10.1017/CBO9780511667206.014

Ministry of Education. (2000). The Guidelines for a 9-Year Joint Curricula Plan. Retrieved from http://www.edu.tw/

Richards, J.C., Platt, J., \& Platt, H. (1998). Longman dictionary of language teaching \& applied linguistics. Hong Kong: Addison Wesley Longman China Limited.

Tarhan, H., \& Balban, S. (2013). Motivation, learner identity, and language learning. Retrieved June, 7, 2014, from https://www.academia.edu/5147924/Motivation_Learner_Identityand_Language_Learning

Wu, G.C. (2002). Foreign language anxiety of EFL elementary school learners: A case study in Taipei County. Retrieved November 27, 2002, from http://datas.ncl.edu.tw/ theabs/00/

\section{Appendix 1.}

\section{Questionnaire}

Instruction : Please answer and check the items that apply to you.

\section{PART I. Something About Yourself}

1. Sex: Female Male

2. How old are you?

3. Have you studied English?

- Yes

If yes, how long have you studied English?

- No (Please skip to question 5 directly.)

4. How often do you study English?

- once a week twice a week other

5. Have you ever been to an English speaking country?

- Yes $\rightarrow$ How long did you stay there?

- No

\section{PART II English Learning \& You}

1. What do you think is the main reason for you to learn English?

(Please check only one of the selections below)

- It's fun to learn English.

- Your parents require you to learn English. 
- English is a required subject in school, and therefore, all of the students have to learn English.

- Most of your friends are learning English so that you want to learn English.

- Other

2. Did your parents require you to learn English? If yes, what do you think about it?

3. Did your parents ask your opinion about whether you want to learn English?

$$
\text { - Yes }
$$
If yes, what do you think about it?

- No

4. Are you happy to learn English?
- Yes
- No

\begin{tabular}{|l|l|}
\hline \multicolumn{1}{|c|}{ If your answer is YES } & Check possible reasons \\
\hline 1) English class is interesting. & \\
\hline 2) I like my English teacher's style of teaching. & \\
\hline 3) There are a lot of games in English class. & \\
\hline $\begin{array}{l}\text { 4) The English textbook is intriguing. It is full of pictures, and various } \\
\text { topics. }\end{array}$ & \\
\hline 5) I am very interested in the English language & \\
\hline 6) I learn English better than other subjects. & \\
\hline
\end{tabular}

OR

\begin{tabular}{|l|l|}
\hline \multicolumn{1}{|c|}{ If your answer is No } & Check possible reasons \\
\hline 1) English class is as boring as other classes. & \\
\hline $\begin{array}{l}\text { 2) It is tedious to learn grammar rules and vocabulary } \\
\text { taught by my English teacher. }\end{array}$ & \\
\hline 3) The text of English is so difficult that I don't understand it at all. & \\
\hline 4) I find no reason to learn English. & \\
\hline 5) English is the most difficult subject for me. & \\
\hline
\end{tabular}

5. Which language do you prefer to learn? English or Mandarin?
- English
- Mandarin
- Please explain your reason.

6. If you don't learn English well, will your parents blame you?

- Yes 
- No

7. Do you feel stressed about learning English? Please explain your answer.

- Yes because

- No because

8. What do you think is the most difficult part of learning English?

- Pronunciation

- Speaking

- Memorizing vocabulary

- Understanding what Americans are talking about

- Learning how to write English

9. People who speak English well are usually smart. Do you agree with this statement?

- Yes__ because

- No __ because

10. Do you agree with the government's policy that all third to sixth graders in primary schools must learn English? Why or why not?

11. In regard to question 10, do you think it is fair to be required to learn English? Please also explain your reason. 